\title{
Spatial distribution, temporal variation and risks of parabens and their chlorinated derivatives in urban surface water in Beijing, China
}

\author{
Wenhui $\mathrm{Li}^{\mathrm{a}}$, Lihong Gao ${ }^{\mathrm{a}}$, Yali Shi ${ }^{\mathrm{b}}$, Yuan Wang ${ }^{\mathrm{b}}$, Jiemin Liu ${ }^{\mathrm{a}, *}$, Yaqi Cai ${ }^{\mathrm{b}, *}$ \\ a School of Chemistry and Biological Engineering, University of Science and Technology Beijing, Beijing 100083, China \\ ${ }^{\mathrm{b}}$ State Key Laboratory of Environmental Chemistry and Ecotoxicology, Research Center for Eco-Environmental Science, Chinese Academy of Sciences, Beijing 100085, China
}

\section{H I G H L I G H T S}

- Parabens and chlorinated parabens are ubiquitous in surface water in Beijing.

- Octylparaben with longer chain was

firstly detected in surface water.

- Untreated sewage discharge was the

main source of parabens in river.

- Parabens exhibited a different seasonal variation from chlorinated derivatives.

- The risks of target compounds are negligible at environmentally relevant levels.

\section{G R A P H I C A L A B S T R A C T}

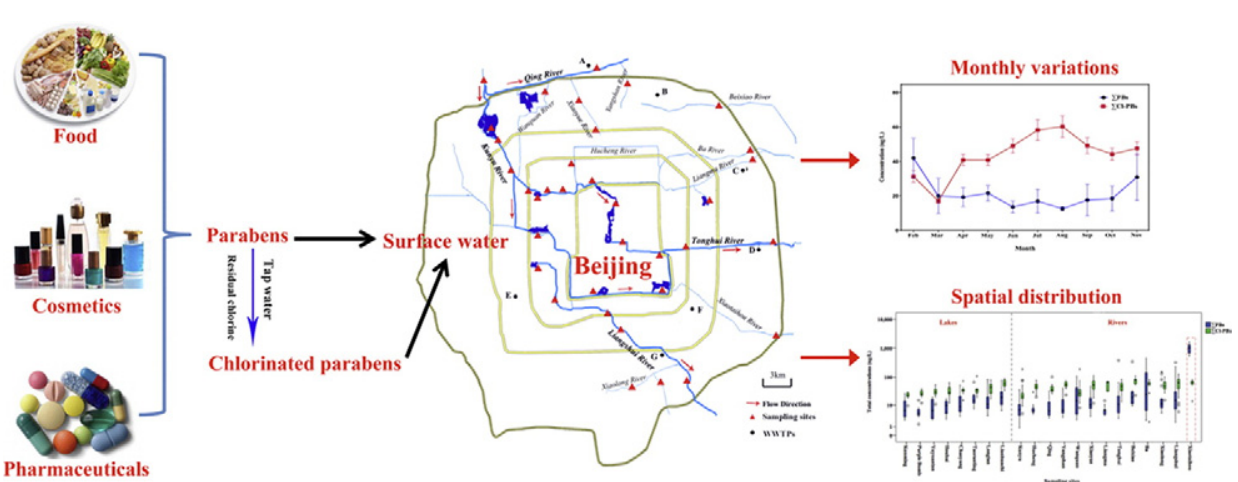

\begin{abstract}
A B S T R A C T
The occurrence and distribution of 13 target compounds, including eight parabens, four chlorinated parabens and p-hydroxybenzoic acid (PHBA), were detected in surface water samples at 35 sampling sites in the Beijing River system, China. The surface water samples were collected from the main rivers and lakes in the urban area monthly from July 2013 to June 2014 (except the frozen period). Laboratory analyses revealed that parabens were ubiquitous in the surface water of Beijing. PHBA was the predominant compound in the surface water samples, with the average concentration of $239 \mathrm{ng} \mathrm{L}^{-1}$, followed by the total amount of chlorinated parabens (average $50.1 \mathrm{ng} / \mathrm{L}$ ) and parabens (average $44.3 \mathrm{ng} / \mathrm{L}$ ). It is noteworthy that octylparaben with longer chain was firstly detected in the surface water. Significant difference was observed for paraben concentrations from different sampling sites, and the highest level of parabens was found in the Xiaotaihou River, which was mainly due to the untreated sewage discharge. Seasonal variation of target compounds in the urban surface water was also studied, and parabens exhibited a different temporal variation from chlorinated derivatives. A combination of factors including high residual chlorine level and water temperature as well as intense ultraviolet radiation might enhance the persistence of chlorinated parabens in chlorinated water during the wet season. Risk assessment showed that parabens and their chlorinated derivatives are not likely to produce biological effects on aquatic ecosystems at current levels in the surface water of Beijing.
\end{abstract}

(c) 2015 Elsevier B.V. All rights reserved.

\footnotetext{
* Corresponding authors.

E-mail addresses: liujm@ustb.edu.cn (J. Liu), caiyaqi@rcees.ac.cn (Y. Cai).
} 


\section{Introduction}

Parabens, alkyl and aryl esters of $p$-hydroxybenzoic acid (PHBA), are extensively used as preservatives in cosmetics, food, pharmaceuticals and industrial products (Gorga et al., 2013; Guo and Kannan, 2013; Liao and Kannan, 2014). These compounds were traditionally considered as ideal preservatives because of their low toxicity, chemical stability, wide spectrum of antibacterial activity, and low production costs (Haman et al., 2015; Soni et al., 2005). However, more and more studies have demonstrated that parabens are an emerging group of endocrine-disrupting chemicals, which may modulate or disrupt the endocrine system to affect the reproductive system, cause immune dysfunction, and produce developmental and behavioral disorders (Kang et al., 2013; Karpuzoglu et al., 2013; Meeker et al., 2011; Oishi, 2002; Piao et al., 2014; Soni et al., 2005). In addition, several studies have reported that parabens were associated with breast cancer etiology, and lead to a potential increase in breast cancer incidence (Darbre et al., 2004; Darbre and Harvey, 2014; Harvey, 2004). Moreover, conventional toxicity tests also show that parabens were toxic to aquatic organisms, such as algae, invertebrate and fish (Bazin et al., 2010; Dobbins et al., 2009; Yamamoto et al., 2011).

As one of the most common preservatives, large amounts of parabens are continuously released into the environment via domestic and industrial wastewater. Although parabens are readily biodegradable, most of them can be replaced by ongoing wide use, leading their pseudo-persistence in the environment. Due to their undesirable effects on human health and aquatic organisms, the occurrence and behavior of parabens in the aquatic environment have been receiving particular attention (Alvarez-Rivera et al., 2014). Until now, limited research has been conducted regarding the occurrence of parabens in surface water, such as the Ebro River in Spain (Gorga et al., 2013), Taff River in UK (Kasprzyk-Hordern et al., 2008), Glatt River in Switzerland (Jonkers et al., 2009), urban streams in Tokushima and Osaka, Japan (Kimura et al., 2014) as well as Pearl River in China (Peng et al., 2008), indicating their ubiquitous distribution in aquatic environment at $\mathrm{ng} / \mathrm{L}$ to $\mu \mathrm{g} / \mathrm{L}$ level (Bledzka et al., 2014). However, most of them were mainly concentrated on the improvement of analytical methods, and only a single sampling campaign was performed in one or several rivers, making the robustness of their conclusions to be compromised. Additionally, due to the lack of standards, limited data was available on the presence of chlorinated parabens in surface water, which are considerably more stable in environment and more toxic to aquatic organisms than their corresponding parent parabens (Bledzka et al., 2014; Terasaki et al., 2009b). Moreover, there are relatively few studies on PHBA, the main metabolite and hydrolysis product of all parabens, in surface water (Blanco et al., 2009). Nevertheless, chlorinated parabens and PHBA may be two noteworthy ways of the introduction of parabens into the aquatic environment (Haman et al., 2015). In order to better understand the behavior of parabens in surface water, the chlorinated derivatives and metabolite should be simultaneously determined (Terasaki et al., 2009b).

Beijing, the capital of China, is one of the most populous cities in the world, with a huge population of 20.693 million in 2012 (Wang et al., 2015). Owing to the large population, the consumption of various productions containing parabens is expected to be massive in this densely populated city. It is reported that large quantities of domestic sewage (about 3.3 million tons per day) were produced from residential areas. However, only $83 \%$ of wastewater was treated in the wastewater treatment plants (WWTPs), and the rest is directly discharged into the waterbody (Dai et al., 2015). Although parabens can be effectively removed during conventional sewage treatments (>90\%) (GonzalezMarino et al., 2011; Jonkers et al., 2009; Ramirez et al., 2012), a small percentage of parabens can still be observed in effluents and may reach the aquatic environment ( $\mathrm{Li}$ et al., 2015). Consequently, the urban rivers and lakes in Beijing would suffer serious parabens contamination. However, no earlier studies have reported the occurrence of parebens in urban surface waters in Beijing, China.
In this study, 13 target compounds, including eight parabens, PHBA, and four chlorinated derivatives, were simultaneously determined in 350 surface water samples collected from urban rivers and lakes in Beijing. The objectives of the research are to investigate the occurrence, spatial and temporal variations of parabens in urban surface waters, search possible sources of parabens in the aquatic environment, and evaluate the potential risks of these compounds to aquatic organisms. To our best knowledge, this is the first study demonstrating the ubiquitous occurrence of parabens and their chlorinated derivatives in surface water in China.

\section{Materials and methods}

\subsection{Standards and reagents}

The methanol and acetonitrile from Fisher Scientific (Pittsburgh, PA, USA) are all of HPLC grade; ammonium acetate (99\%) was purchased from Alfa Aesar (Ward Hill, MA). All purity water $\left(>18.2 \mathrm{M} \Omega \cdot \mathrm{cm}^{-1}\right.$ ) was prepared with Milli-Q Advantage A10 system (Millipore, USA).

Chemical standards of p-Hydroxybenzoic acid (PHBA, 100\%), Methyl paraben (MeP, 97.5\%), Ethyl paraben (EtP, 99.0\%), Propyl paraben (PrP, 99.3\%), Butyl paraben (BuP, 100\%), Pentyl Paraben (PeP, 98.0\%), Heptyl paraben (HeP, 99.0\%), Benzyl paraben (BzP, 100\%), Octyl paraben (OcP, 98.0\%), Methyl 3-chloro-4-hydroxybenzoate (3-Cl-MeP, 98.0\%), Methyl 3,5-dichloro-4-hydroxybenzoate (3,5-2Cl-MeP, 98.0\%), Ethyl 3-chloro-4-hydroxybenzoate (3-Cl-EtP, 97.0\%) and Ethyl 3,5-dichloro-4-hydroxybenzoate (3,5-2Cl-EtP, 98.0\%) were purchased from AccuStandard Inc. (New Haven, CT, USA).

The following isotopically labeled compounds were used as surrogate standards $\left(500.0 \mu \mathrm{g} / \mathrm{L}\right.$ in methanol): $\mathrm{p}$-Hydroxybenzoic acid- $\mathrm{d}_{4}$ $\left(\right.$ PHBA- $\left.\mathrm{d}_{4}\right)$, Methyl Paraben- $\mathrm{d}_{4}\left(\right.$ MeP- $\left.\mathrm{d}_{4}\right)$, Ethyl Paraben- $\mathrm{d}_{5}\left(\right.$ EtP- $\left.\mathrm{d}_{5}\right)$, Propyl Paraben- $\mathrm{d}_{7}\left(\mathrm{PrP}_{\mathrm{P}} \mathrm{d}_{7}\right)$, Paraben- $\mathrm{d}_{9}\left(\mathrm{BuP}_{\mathrm{P}} \mathrm{d}_{9}\right)$ and Benzyl Paraben- $\mathrm{d}_{9}$ $\left(\mathrm{BzP}_{-} \mathrm{d}_{7}\right)$, which were purchased from Toronto Research Chemicals (Oakville, ON, Canada). Information on physicochemical properties of the target parabens is provided in Table S1 in the Supplementary materials.

\subsection{Sample collection}

The study area is sited in the urban of Beijing (Fig. 1). Monthly sampling campaigns were performed at 35 sampling sites in the Beijing River system from July 2013 to June 2014 (except January and December in frozen period). Of which, sites R1-R8 were located in the Kunyu River, R9-R11 were located in the Tonghui River, R22-R25 were located in the Liangshui River, R26-R27 were situated in the Xiaolong River, and R13-R17 were situated in the Qing River and its tributaries. The rest of sampling sites located at Xiaotaihou River (R21), Liangma River (R20), Ba River (R19), Beixiao River (R18), and Hucheng River (R12). Eight lakes were also selected as the target sampling sites, including Kunming Lake (L1), Purple Bambo Lake (L2),Houhai Lake (L3), Yuyuantan Lake (L4), Taoranting Lake (L5), Longtan Lake (L6), Chaoyang Park Lake (L7), and Lianhuachi Lake (L8).

Most of the riverbeds were reinforced with concrete and periodically dredged, so only water samples were collected in this study. A total of 350 surface water samples were obtained in 10 sampling campaigns. All of the surface water samples were collected in 1-L polypropylene bottles rinsed with water and methanol. Immediately after being transported to the laboratory, the samples were stored at $4{ }^{\circ} \mathrm{C}$ and pretreated as soon as possible.

\subsection{Sample preparation and analysis}

Target compounds were extracted from water samples using AutoTrace SPE 280 (Dionex, USA) with an Oasis HLB cartridge ( $6 \mathrm{~mL}$, $200 \mathrm{mg}$; Waters, USA), as described in our previous study with some 




Fig. 1. Study areas and sampling sites in the main rivers and lakes in Beijing, China.

modifications (Li et al., 2015). Briefly, the water samples were adjusted to $\mathrm{pH} 2$ with $1.0 \mathrm{M} \mathrm{H}_{2} \mathrm{SO}_{4}$ and $\mathrm{NaOH}$, and $20 \mathrm{ng}$ surrogate standards (PHBA- $\mathrm{d}_{4}, \mathrm{MeP}-\mathrm{d}_{4}, \mathrm{EtP}-\mathrm{d}_{5}$, PrP- $\mathrm{d}_{7}, \mathrm{BuP}-\mathrm{d}_{9}$ and $\mathrm{BzP}-\mathrm{d}_{7}$ ) were added to $500 \mathrm{~mL}$ water sample before the mixture were extracted with the Oasis HLB cartridge. The HLB cartridges were conditioned with $5 \mathrm{~mL}$ methanol and $5 \mathrm{~mL}$ DI water. Then, $500 \mathrm{~mL}$ of samples were passed through at a flow rate of $5 \mathrm{~mL} / \mathrm{min}$. After that, the cartridges were washed with $6 \mathrm{~mL}$ DI water, dried under a nitrogen stream for $30 \mathrm{~min}$, and then eluted with $6 \mathrm{~mL}$ of methanol. The eluent was concentrated to $1 \mathrm{~mL}$ with a stream of nitrogen at $35^{\circ} \mathrm{C}$. Finally, the concentrate was filtered through a $0.45 \mu \mathrm{m}$ nylon membrane (Whatman, Maidstone, U.K.), and an aliquot ( $15 \mu \mathrm{L}$ ) of this solution was injected into the high-performance liquid chromatography-electrospray ionization tandem mass spectrometry (HPLC-ESI MS/MS) system for analysis.

Chemical analysis was performed with an Ultimate 3000 HPLC system (Sunnyvale, CA, USA) coupled to an API 3200 triple quadrupole mass spectrometer (Foster City, CA, USA) equipped with an electrospray ionization source. An Acclaim Mixed-Mode HILIC-1 column ( $3 \mu \mathrm{m}$, $2 \mathrm{~mm} \times 150 \mathrm{~mm}$; Thermo, USA) was used as the analytical column at a flow rate of $0.20 \mathrm{~mL} / \mathrm{min}$. Acetonitrile was used as mobile phase A, and $0.1 \%$ ammonium formate in water was used as mobile phase $\mathrm{B}$. The gradient program was as follows: the mobile phase starting conditions were $40 \%$ of A for $2.0 \mathrm{~min}$, and A was increased to $55 \%$ within 3.0 min before being increased to $100 \%$ within $6.0 \mathrm{~min}$; $100 \%$ of $A$ for
$4.0 \mathrm{~min}$, followed by returning to the initial compositions within $1 \mathrm{~min}$ and then the maintenance for $9.0 \mathrm{~min}$.

The MS system was operated in the negative electrospray ionization and multiple reactions monitoring (MRM) mode. The MS/MS parameters were optimized as follows: curtain gas pressure, 0.07 MPa; collision gas pressure, $0.02 \mathrm{MPa}$; ion spray voltage, $-4500 \mathrm{~V}$; temperature, $450{ }^{\circ} \mathrm{C}$; gas $1,0.31 \mathrm{MPa}$; and gas 2, $0.31 \mathrm{MPa}$. Other parameters of MS/MS and ion pair are listed in Table S2.

\subsection{Quality assurance and quality control}

All equipment and containers were rinsed with methanol and purified water to avoid sample contamination. For each set of samples, one procedure blank and one independent check standard were evaluated for background contamination and system performance. The internal standard method was used for quantification of each target compound. Method detection limits (MDLs) that calculated as 3 times signal-tonoise for each compound in the actual samples ranged from 0.02 to $0.4 \mathrm{ng} / \mathrm{L}$. The calibration curve was generated across a wide range of concentrations $(0.1-200 \mu \mathrm{g} / \mathrm{L})$ with strong linearity $\left(r^{2}>0.99\right)$. Recoveries of target compounds in water samples were calculated to assess the accuracy of the method, and the recoveries ranged from 85.9 to $104 \%$. Detailed information about recoveries, correlation coefficients and limits of detection of target compounds are listed in Table S3 in the Supplementary materials. 


\subsection{Statistical analysis}

Statistical analyses were performed with IBM PASW Statistics 18.0 (SPSS Inc., 1993-2007). Concentrations of target compounds below the MDLs were assigned a value of zero for data analysis. The total concentration of parabens ( $\sum$ PBs ) was the total amount of eight individual parabens, and $\sum \mathrm{Cl}-\mathrm{PBs}$ was the total amount of four individual chlorinated parabens analyzed in this study. The normality test of the data was analyzed using a Kolmogorov-Smirnov test. A nonparametric Spearman correlation was performed to assess correlations among the concentrations of several parabens in surface water. Comparison of concentrations was performed using the nonparametric KruskalWallis test. The significant difference was considered at $p<0.05$.

\subsection{Risk characterization}

In the present study, hazard quotients (HQs) were applied to evaluate the ecological risk of parabens and chlorinated derivatives in surface water on organisms. In general, HQs of target compounds in the aquatic environment are calculated following the formula (Liu et al., 2015; Yan et al., 2013):

$\mathrm{HQ}=\mathrm{MEC} / \mathrm{PNEC}$

where MEC is the measured environmental concentration, and PNEC is the predicted no effect concentration in water. The PNEC was calculated using the following formula (Hernando et al., 2006):

$\mathrm{PNEC}=\left(\mathrm{LC}_{50}\right.$ or $\left.\mathrm{EC}_{50}\right) / \mathrm{AF}$

where $\mathrm{LC}_{50}$ or $\mathrm{EC}_{50}$ is the median effective concentration value, and $\mathrm{AF}$ is an appropriate safety factor of 100 and 1000 for chronic and acute toxicity, respectively (Yamamoto et al., 2011; Yan et al., 2013). To calculate values for the worst-case scenario, highest concentrations of parabens detected in surface water, as well as the most sensitive values of $\mathrm{LC}_{50}$ or $\mathrm{EC}_{50}$ obtained from the available literature were applied (Leung et al., 2012). If the value of $H Q>1$, the ecological impact is expected for the target compounds (Mutiyar and Mittal, 2014).

\section{Results and discussion}

\subsection{Concentrations of parabens, chlorinated parabens, and PHBA in surface water}

Concentrations and detection frequency of 13 target compounds in urban surface water from Beijing are summarized in Table 1. As can be seen, a total of 12 compounds, including seven parabens (MeP, EtP, $\mathrm{PrP}, \mathrm{BuP}, \mathrm{BzP}, \mathrm{HeP}$ and OcP), four chlorinated parabens (3-Cl-Mep, 3-Cl-Etp, 3,5-2Cl-MeP and 3,5-2Cl-EtP), and their main hydrolysis product (PHBA), were detected in water samples. The concentrations of PHBA, parabens ( $\sum$ PBs), and chlorinated parabens ( $\sum \mathrm{Cl}-\mathrm{PBs}$ ) ranged from $<$ LOD to $1,625 \mathrm{ng} / \mathrm{L}$ (average $239 \mathrm{ng} / \mathrm{L}$ ), from 0.82 to $1654 \mathrm{ng} / \mathrm{L}$ (average $50.1 \mathrm{ng} / \mathrm{L}$ ) and from 1.95 to $191 \mathrm{ng} / \mathrm{L}$ (average $44.3 \mathrm{ng} / \mathrm{L}$ ), respectively. Composition distribution of PHBA, $\sum$ PBs and $\sum \mathrm{Cl}-\mathrm{PBs}$ in different water samples was illustrated in Fig. S1. PHBA was the predominant compound (71.7\%) in surface water samples, whereas parabens (15.0\%) and chlorinated parabens (13.3\%) accounted for a minor contribution to the total concentrations.

PHBA. The high level of PHBA in surface water is consistent with a previous study that considerable concentration of PHBA was detected in river water samples from Galicia, Spain (39-133 ng/L) (Blanco et al., 2009). As the main metabolite and hydrolysis product of parabens, PHBA is also a widely used preservative in food and personal care products (Diaz et al., 2008; Hoberg et al., 2000). In addition, it is not only ubiquitous in green plants, but also an intermediate in the synthesis of commercially chemical products (McQualter et al., 2005; Zhao and
Table 1

Concentrations of targeted compounds in urban surface water samples (ng/L).

\begin{tabular}{llllll}
\hline Analytes & Mean & Median & Maximum & Minimum & Frequency (\%) \\
\hline MeP & 22.4 & 6.45 & 920 & 0.81 & 100 \\
EtP & 7.68 & 0.54 & 294 & n.d. & 74.4 \\
PrP & 19.0 & 0.77 & 565 & n.d. & 70.8 \\
BuP & 0.98 & n.d. & 41.5 & n.d. & 35.0 \\
PeP & n.d. & n.d. & n.d. & n.d. & n.d. \\
HeP & 0.02 & n.d. & 2.94 & n.d. & 1.11 \\
BzP & 0.05 & n.d. & 3.93 & n.d. & 7.78 \\
OcP & 0.03 & n.d. & 4.89 & n.d. & 10.3 \\
3-Cl-MeP & 0.06 & n.d. & 5.05 & n.d. & 10.6 \\
3,5-2Cl-MeP & 13.0 & 9.35 & 80.0 & 0.64 & 100 \\
3-Cl-EtP & 0.20 & n.d. & 18.4 & n.d. & 6.67 \\
3,5-2Cl-EtP & 31.0 & 26.8 & 128 & 1.30 & 100 \\
PHBA & 239 & 175 & 1625 & n.d. & 99.7 \\
$\sum$ PBs & 50.1 & 9.44 & 1654 & 0.82 & 100 \\
$\sum$ Cl-PBs & 44.3 & 38.4 & 191 & 1.95 & 100 \\
\hline
\end{tabular}

n.d. $=$ not detected.

Fang, 2005). In fact, it is reported that most parabens are stable in acidic solutions, and prone to hydrolysis in alkaline conditions (Eriksson et al., 2009; Lin et al., 2011). In this study, the pH values of surface water samples are neutral or weakly alkaline with the mean value ranged from pH 6.79 to 7.68. Accordingly, hydrolysis is not expected to be an important fate process of most parabens in aquatic environment (Haman et al., 2015). Additionally, as shown in Table 2, the concentration of PHBA showed no significant correlation with $\sum$ PBs $(R=0.261, P>$ 0.05 ). As mentioned above, the high level of PHBA detected in surface water probably resulted from its massive consumption in various products. Considering the wide sources of PHBA in environment, the concentration of PHBA maybe does not accurately and adequately reflect the pollution levels of parabens in surface water.

Parabens. Among eight paraben analogs, seven parabens (MeP, EtP, $\mathrm{PrP}, \mathrm{BuP}, \mathrm{BzP}, \mathrm{HeP}$ and $\mathrm{OcP}$ ) were detected in the water samples, while PeP was not found in any sample due to its rare use in China, which will be excluded from the following discussion. Composition distribution of individual parabens and chlorinated parabens was shown in the Fig. 2. MeP and PrP were the predominant parabens in surface water, with a mean concentration of 22.4 and $19.0 \mathrm{ng} / \mathrm{L}$, respectively. These two parabens accounted for $44.7 \%$ and $37.9 \%$ of the total paraben concentrations, which is in agreement with their wide use in numerous cosmetic products in China (Guo et al., 2014). The next two frequently used parabens, EtP (7.68 ng/L) and BuP $(0.98 \mathrm{ng} / \mathrm{L})$, were also detected in most river samples. In contrast, BzP (0.05 ng/L), OcP (0.03 ng/L) and HeP (0.02 ng/L) were only present at marginal levels in surface water, which can be explained by their low frequency of use and water solubility (Table S1). In general, the relative levels of the seven measured parabens reflect their consumption pattern in this area. It is worth to mention that OcP with longer chain was firstly detected in surface water samples in this study. Due to the strong estrogenic activity and persistence in the environment (Li et al., 2015), more attention should be paid to the occurrence and behavior of OcP in aquatic environment.

The concentrations of main target parabens detected in this study were lower than or similar to those previously reported in the Pearl River, Guangzhou, China (MeP: n.d.-1062 ng/L; PrP: n.d.-3142 ng/L) (Peng et al., 2008) and Tokushima and Osaka, Japan (MeP: 25676 ng/L; EtP: <1.3-64 ng/L; PrP: <0.8-207 ng/L; BuP: <0.6-163 ng/L) (Yamamoto et al., 2011). However, the concentrations of these parabens were at least one order of magnitude higher than those in Ebro River, Spain (MeP: 1.4-27 ng/L; EtP: n.d.-13 ng/L; PrP: 0.515 ng/L; BuP: n.d.-1.1 ng/L) (Gorga et al., 2013), Glatt River, Switzerland (MeP: 3.1-17 ng/L; EtP: <0.3-1.6 ng/L; PrP: <0.5-5.8 ng/L; BuP: $<0.2-2.8 \mathrm{ng} / \mathrm{L}$ ) (Jonkers et al., 2009), and Tamiraparani River, India (MeP: n.d.-22.8 ng/L; EtP: <2.47-147 ng/L; PrP: <n.d-57 ng/L; BuP: n.d) 
Table 2

Spearman correlations among concentrations of individual parabens measured in surface water $(\mathrm{n}=350)$

\begin{tabular}{|c|c|c|c|c|c|c|c|c|c|}
\hline Analytes & $\mathrm{MeP}$ & EtP & $\operatorname{PrP}$ & BuP & $\mathrm{HeP}$ & $\mathrm{BzP}$ & OcP & PHBA & $\sum \mathrm{PBS}$ \\
\hline $\mathrm{MeP}$ & 1.000 & & & & & & & & \\
\hline EtP & $0.388^{* *}$ & 1.000 & & & & & & & \\
\hline PrP & $0.470^{* *}$ & $0.477^{* *}$ & 1.000 & & & & & & \\
\hline BuP & $0.427^{* *}$ & $0.371^{* *}$ & $0.470^{* *}$ & 1.000 & & & & & \\
\hline $\mathrm{HeP}$ & -0.010 & -n.d.3 & 0.037 & -0.076 & 1.000 & & & & \\
\hline $\mathrm{BzP}$ & -0.035 & -0.030 & -0.044 & -0.031 & 0.075 & 1.000 & & & \\
\hline OcP & 0.103 & 0.064 & 0.024 & 0.171 & -0.036 & -0.027 & 1.000 & & \\
\hline PHBA & 0.273 & 0.161 & 0.253 & 0.292 & -0.06 & -0.090 & 0.134 & 1.000 & \\
\hline$\sum \mathrm{PBS}$ & $0.915^{* *}$ & $0.570^{* *}$ & $0.663^{* *}$ & $0.494^{* *}$ & 0.037 & -0.022 & 0.105 & 0.261 & 1.000 \\
\hline
\end{tabular}

** Correlation is significant at the 0.01 level (2-tailed).

(Ramaswamy et al., 2011), indicating that the level of parabens in surface water of Beijing was relatively high.

Previous studies have reported that combinations of two or more parabens are often used in foods, cosmetics, and pharmaceuticals to enhance antimicrobial activity and protect against a broad range of microorganisms (Gasperi et al., 2014; Guo et al., 2014; Jonkers et al., 2010; Liao et al., 2013). As shown in Table 2, a nonparametric Spearman correlation analysis was performed on the concentrations of seven parabens. Significantly positive correlation was observed among the concentrations of MeP, EtP, $\operatorname{PrP}$, and $\mathrm{BuP}(\mathrm{R}=0.37-0.47, p<0.01)$, indicating similarity in their sources in surface water. However, no correlation was found between BzP, OcP, HeP and other four frequently used parabens (MeP, EtP, PrP, BuP), probably reflecting different sources and consumption practices of these parabens in Beijing.

Chlorinated parabens. As shown in the Figs. 2, 3,5-2Cl-EtP and 3,5-2Cl-MeP were the dominant chlorinated parabens in surface water, with a mean concentration of 31.0 and $13.0 \mathrm{ng} / \mathrm{L}$, respectively, which were two or three orders of magnitude higher than that of the mono-chlorinated parabens, 3-Cl-EtP (0.20 ng/L) and 3-Cl-MeP $(0.06 \mathrm{ng} / \mathrm{L})$. In addition, we also found that the detection frequencies of di-chlorinated parabens, 3,5-2Cl-EtP (100\%) and 3,5-2Cl-MeP (100\%) were evidently higher than those of mono-chlorinated parabens, 3-Cl-EtP (10.6\%) and 3-Cl-MeP (6.7\%), in river samples (Table 1 ). These results may be well explained by the fact that the dichlorinated parabens are more stable than mono-chlorinated ones in the aquatic environment (Gonzalez-Marino et al., 2011). Interestingly, significant positive correlations were observed between the concentrations of 3,5-2Cl-MeP and MeP $(R=0.350, p<0.01)$, as well as 3,5-2Cl-EtP and $\operatorname{EtP}(R=0.321, p<0.01)$ in these samples (Table $S 4)$. These results suggest that these chlorinated derivatives were originated when personal care products containing parabens reached chlorinated water, and then released into aquatic environments (Albero et al., 2012; Terasaki et al., 2009a).

To date, limited information is available on the levels of chlorinated parabens in river and lake water due to the lack of commercial standards. Lower concentrations of chlorinated parabens (3-Cl-Mep: n.d.; 3-Cl-Etp; n.d.; 3,5-2Cl-MeP: $6.1 \mathrm{ng} / \mathrm{L}$; 3,5-2Cl-EtP: n.d.) were reported to occur in Japanese river (Terasaki et al., 2012). Compared with other environmental water samples, the levels of chlorinated derivatives in this study were one to two orders of magnitude higher than those found in swimming pool water (3,5-2Cl-MeP: n.d.; 3,5-2Cl-EtP: n.d.) (Terasaki and Makino, 2009), and effluents of wastewater treatment plants (3,5-2Cl-MeP: $2.6 \mathrm{ng} / \mathrm{L})$, even in the same order of magnitude as those in influents (3,5-2Cl-MeP: $46 \mathrm{ng} / \mathrm{L}$ ) (Gonzalez-Marino et al., 2011), indicating that the level of chlorinated parabens in surface water samples of Beijing was relatively high. It should be noted that the level of 3,5-2Cl-EtP (mean $31.0 \mathrm{ng} / \mathrm{L}$ ) was detected at higher levels than the corresponding parent compound (EtP: mean $7.68 \mathrm{ng} / \mathrm{L}$ ). Compared to their respective parent compounds, chlorinated parabens are more persistent and show higher acute toxicity to aquatic organisms (Haman et al., 2015). Therefore, more attention should be paid to their potential risks to aquatic organisms.

\subsection{Spatial distribution of parabens and chlorinated derivatives}

The distribution of parabens and chlorinated derivatives in different rivers and lakes was shown in Fig. 3. Significant positive

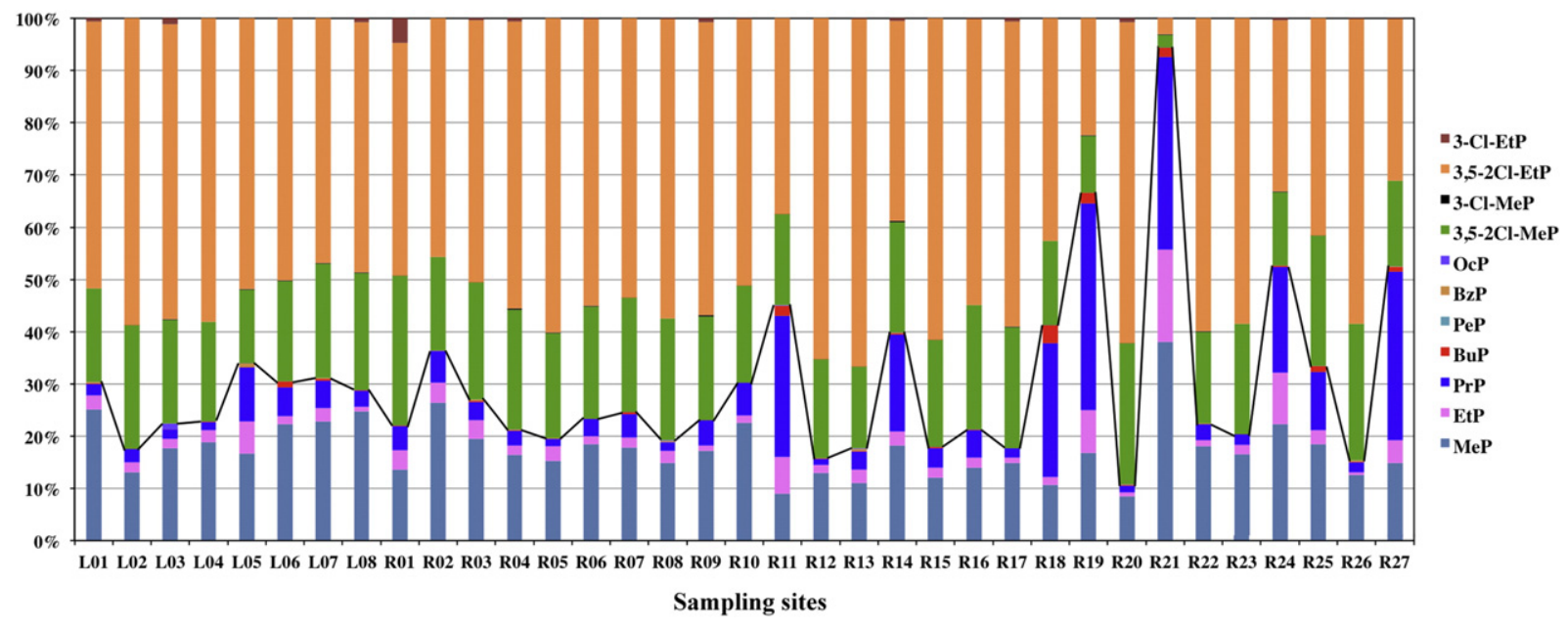

Fig. 2. Composition distribution of individual parabens and chlorinated parabens in 35 sampling sites. 


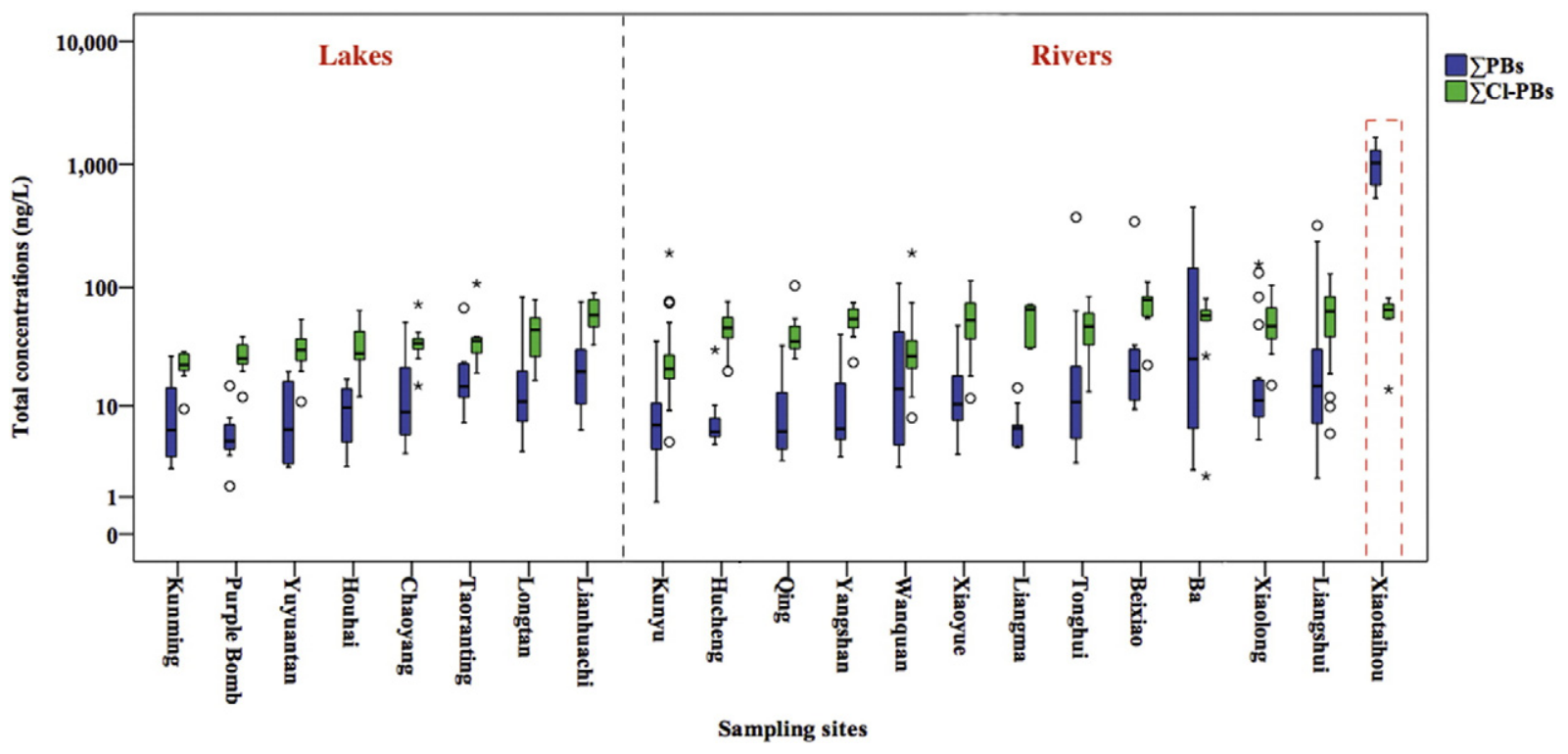

Fig. 3. Box-and-whisker plots of $\sum \mathrm{PBs}$ and $\sum \mathrm{Cl}-\mathrm{PBs}$ in different rivers and lakes of Beijing (ng/L).

correlations were observed between the concentrations of $\sum$ PBs and $\sum \mathrm{Cl}$-PBs $(\mathrm{R}=0.396, p<0.01)$ in these samples, whereas there was a difference between the distribution of parabens and chlorinated derivatives.

The concentrations of $\sum$ PBs ranged from 6.87 to $1029 \mathrm{ng} / \mathrm{L}$ in all samples from the rivers and lakes (Table S5). Statistical analysis revealed that there were significant differences (Kruskal-Wallis test, $p<0.05)$ in concentrations of $\sum$ PBs among the 35 sampling sites. In general, the concentrations of $\sum$ PBs in rivers (R1-R27, mean $60.9 \mathrm{ng} / \mathrm{L}$ ) were higher than those in urban lakes (L1-L8, mean $14.5 \mathrm{ng} / \mathrm{L}$ ), which were situated in urban parks far away from industrial wastewater and municipal sewage. The highest concentration of $\sum$ PBs was found in Xiaotaihou River (R21, $1029 \mathrm{ng} / \mathrm{L}$ ), which is one of the main drainages for wastewater in the south of Beijing. Likewise, high levels of $\sum$ PBs were also detected in Ba River (R19, 105 ng/L), Beixiao River (R18, $51.7 \mathrm{ng} / \mathrm{L}$ ) and Liangshui River (R22-R25, $38.3 \mathrm{ng} / \mathrm{L}$ ). These rivers are located near the outlet of five major WWTPs (B, C, D, F and G), and flow through a densely populated and highly industrialized urban area in Beijing, which may be heavily impacted by large amounts of WWTP effluents, domestic sewage and industrial wastewaters. On the contrary, relatively low level of PBs was observed in Kunyu River (R1-R8, $8.14 \mathrm{ng} / \mathrm{L}$ ), which is an important drinking water source for Beijing residents. Hucheng River (R12, $8.62 \mathrm{ng} / \mathrm{L}$ ), an important recreation watercourse, was also less contaminated, where the point sources of pollution along the river were strictly controlled (Hou et al., 2013).

However, no significant differences were observed in the $\sum \mathrm{Cl}-\mathrm{PBs}$ concentrations among different sampling sites $(p>0.05)$. The concentrations of $\sum \mathrm{Cl}$-PBs ranged from 22.5 to $73.7 \mathrm{ng} / \mathrm{L}$ in surface water samples. Although the highest level of $\sum$ PBs was up to $1029 \mathrm{ng} / \mathrm{L}$ in Xiaotaihou River, the $\sum \mathrm{Cl}-\mathrm{PBs}$ concentration in this river was only $61.5 \mathrm{ng} / \mathrm{L}$, which is similar to or even lower than that in Beixiao River (R18, $73.7 \mathrm{ng} / \mathrm{L}$ ), Liangshui River (R22-R25, $62.6 \mathrm{ng} / \mathrm{L}$ ) and Lianhuachi Lake (L8, $62.2 \mathrm{ng} / \mathrm{L}$ ). Chlorinated parabens are the undesirable byproducts, which are formed by reaction of the parent parabens with residual chlorine in tap water during showering, bathing and swimming, as well as wastewater during the chlorination processes of water treatment (Canosa et al., 2006; Liao et al., 2013). If the residue chlorine was unable to satisfy the further reaction of chlorinated formation, the level of $\sum \mathrm{Cl}$-PBs would be changed little. Although parabens can be easily transformed to chlorinated derivatives in chlorinated water (Westerhoff et al., 2005), the free chlorine levels contained in river water are usually not enough to react with parabens and produce chlorinated derivatives. Thus, the level of $\sum \mathrm{Cl}$-PBs is limited by dosages of free chlorine in river water. It should be noted that the level of $\sum \mathrm{Cl}$-PBs was much higher than that of $\sum$ PBs in most sampling sites (with the exception of Ba River and Xiaotaihou River). This may be attributable to that the chlorinated parabens are more persistent than their corresponding parent compounds in the aquatic environment (Bledzka et al., 2014; Gonzalez-Marino et al., 2011; Terasaki et al., 2012).

In this study, the exceptionally high $\sum$ PBs level in Xiaotaihou River should be concerned. In order to discern possible sources of parabens in this river, additional water samples, including three domestic sewage and one industrial sewage samples from the discharge sites (about 1-km upstream from R21), as well as effluent and influent (raw sewage) of WWTP F, were collected during the last sampling campaign (June 2014) in this study. In general, WWTPs are considered as the major point sources of parabens in the environment due to their incomplete elimination (Bledzka et al., 2014; Regueiro et al., 2009). However, the concentration of $\sum$ PBs in WWTP effluent ( $25.1 \mathrm{ng} / \mathrm{L}$ ), as well as industrial sewage $(87.0 \mathrm{ng} / \mathrm{L})$ were two orders of magnitude lower than that in Xiaotaihou River (1029 ng/L), suggesting that they had a limited contribution to the occurrence of parabens in this river (Fig. S2). We found the composition pattern of parabens in Xiaotaihou River was similar to the WWTP influent and domestic sewage samples (Fig. 4), indicating that the concentration of parabens in this river may be influenced by untreated domestic sewage. In addition, OcP was only found in WWTP influent $(0.33 \mathrm{ng} / \mathrm{L})$ and domestic sewage $(0.08 \mathrm{ng} / \mathrm{L})$, while not detected in effluent or industrial sewage, suggesting that OcP in Xiaotaihou River $(0.10 \mathrm{ng} / \mathrm{L})$ may derived from the discharged raw sewage and domestic sewage. In fact, the Xiaotaihou River is close to the suburban area of Beijing, where the domestic sewage collection rate is relatively low $(<50 \%$ ) (Dai et al., 2015). Accordingly, a large amount of domestic wastewater along the river was directly discharged into the water body, leading to high level of parabens in this river. It's also important to note that the amount of influent may exceed the processing capacity of WWTP F, especially during heavy rainfall, the untreated or partially treated raw sewage was released directly into this river (Ren et al., 2014). Therefore, discharge of domestic wastewater and leakage of 


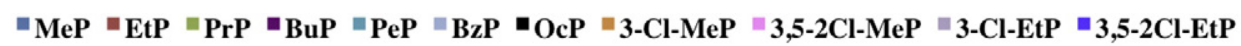

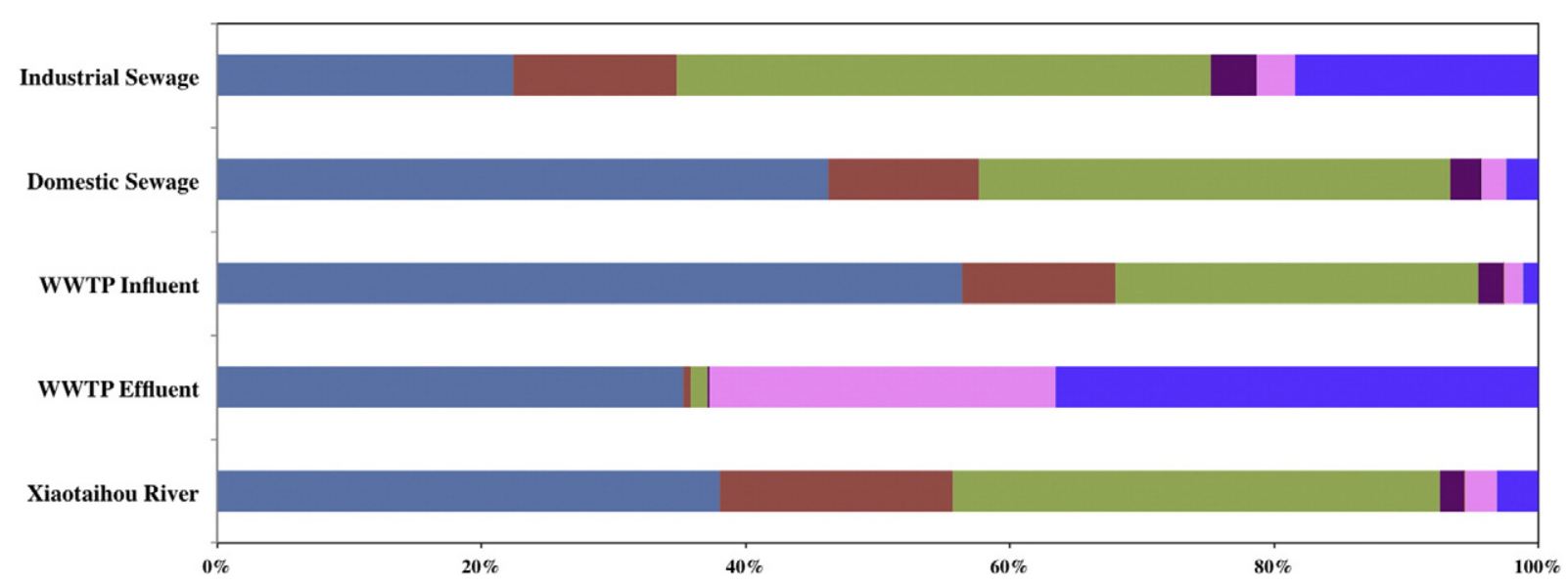

Fig. 4. Composition pattern of parabens and chlorinated parabens in Xiaotaihou River, domestic sewage, industrial sewage, and WWTP effluent and influent samples.

WWTP influent would be the main sources of parabens in Xiaotaihou River. In the future, more intensive sampling campaigns would be performed to accurately ascertain the pollutant inputs in this river.

\subsection{Temporal variation of parabens and chlorinated derivatives}

The temporal variations of parabens and chlorinated derivatives in water samples in Beijing were illustrated in Fig .5. Monthly variations of $\sum$ PBs concentrations were observed in these water samples (Friedman's test, $\mathrm{p}<0.01$ ). It was obvious that lower concentrations of $\sum$ PBs were in the wet season (June to August, 12.6-16.9 ng L ${ }^{-1}$ ), while higher in February (41.6 $\mathrm{ng} \mathrm{L}^{-1}$ ) and November $\left(30.9 \mathrm{ng} \mathrm{L}^{-1}\right)$. This result was consistent with previous studies that the maximum $\sum$ PBs concentrations were observed in rivers during low flow periods, most likely due to less dilution by lower precipitation in the dry season (Loraine and Pettigrove, 2006; Peng et al., 2008).

However, the dilution factor cannot explain why the highest concentration of $\sum \mathrm{Cl}-\mathrm{PBs}$ was still found in the flood season (June to August, 49.0-60.2 $\mathrm{ng} \mathrm{L}^{-1}$ ), with approximately $80 \%$ of the total precipitation concentrated in this period in Beijing (Heeb et al., 2012). It may be explained that more chlorinated derivatives are formed in chlorinated water (tap water and swimming water) in the wet season than those

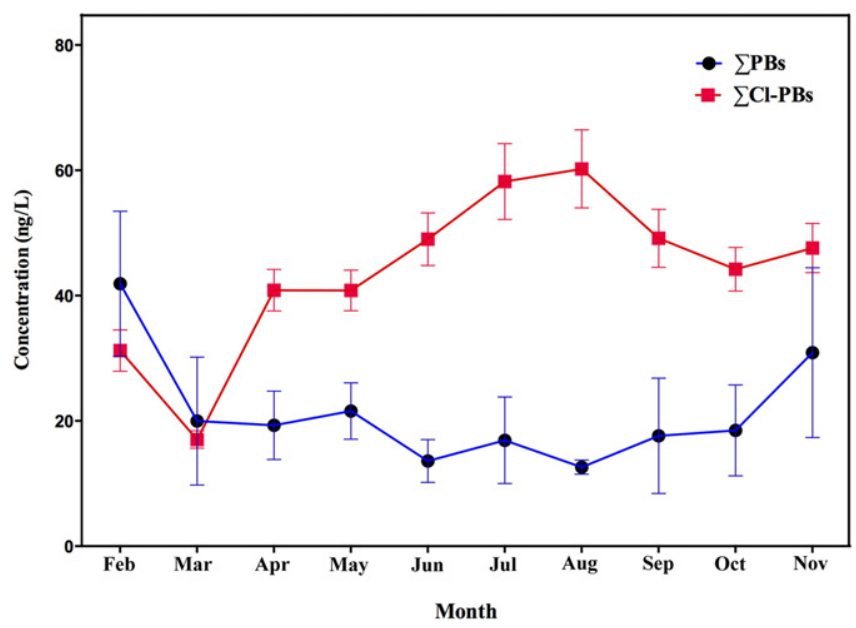

Fig. 5. Monthly variations of $\sum$ PBs and $\sum \mathrm{Cl}$-PBs in surface water samples in Beijing. in dry season, and then introduced into surface water. Several studies have reported that parabens are easily to react with chlorine to produce chlorinated derivatives, and the reaction rate increases with water temperature (Bledzka et al., 2014; Canosa et al., 2006). Laboratory degradation tests also demonstrated that even low levels of free chlorine could increase the photodegradation rate of parabens and enhance the formation of chlorinated derivatives under UV-light (Alvarez-Rivera et al., 2014). In general, the level of free residual chlorine in tap water in summer $(0.64 \mathrm{mg} / \mathrm{L})$ was higher than that in winter $(0.49 \mathrm{mg} / \mathrm{L})$ in Beijing (Wei et al., 2010). Also, more swimming water containing high level of free residual chlorine was discharged into surface water. In addition, the water temperature and ultraviolet radiation in summer are evidently higher and stronger than those in winter. Therefore, high residual chlorine level and water temperature as well as intense ultraviolet radiation in summer may favor the formation of chlorinated derivatives, and

Table 3

Hazard quotients (HQs) for the aquatic organisms as calculated from measured environmental concentrations (MECs) and predicted environmental concentrations (PNECs).

\begin{tabular}{|c|c|c|c|c|}
\hline Analytes & Taxonomic group & PNEC (ng/L) & MEC (ng/L) & HQ \\
\hline \multirow[t]{4}{*}{$\mathrm{MeP}$} & Bacteria & 2,500 & \multirow[t]{4}{*}{920} & 0.368 \\
\hline & Algae & 80,000 & & 0.012 \\
\hline & Invertebrate & 13,100 & & 0.070 \\
\hline & Fish & 14,000 & & 0.066 \\
\hline \multirow[t]{4}{*}{ EtP } & Bacteria & 4,600 & \multirow[t]{4}{*}{294} & 0.064 \\
\hline & Algae & 52,000 & & n.d.6 \\
\hline & Invertebrate & 7,400 & & 0.040 \\
\hline & Fish & 63,000 & & n.d.5 \\
\hline \multirow[t]{4}{*}{$\operatorname{PrP}$} & Bacteria & 260 & \multirow[t]{4}{*}{565} & 2.173 \\
\hline & Algae & 36,000 & & 0.016 \\
\hline & Invertebrate & 2,000 & & 0.283 \\
\hline & Fish & 4,900 & & 0.115 \\
\hline \multirow[t]{4}{*}{$\mathrm{BuP}$} & Bacteria & 1,200 & \multirow[t]{4}{*}{41.5} & 0.035 \\
\hline & Algae & 9,500 & & n.d.4 \\
\hline & Invertebrate & 470 & & 0.088 \\
\hline & Fish & 3,100 & & 0.013 \\
\hline \multirow[t]{4}{*}{$\mathrm{BzP}$} & Bacteria & 110 & \multirow[t]{4}{*}{3.93} & 0.036 \\
\hline & Algae & 1,200 & & n.d.3 \\
\hline & Invertebrate & 1,000 & & n.d.4 \\
\hline & Fish & 730 & & n.d.5 \\
\hline \multirow[t]{2}{*}{ 3,5-2Cl-MeP } & Bacteria & 3,000 & \multirow[t]{2}{*}{80} & 0.027 \\
\hline & Invertebrate & 16,000 & & n.d.5 \\
\hline \multirow[t]{2}{*}{ 3,5-2Cl-EtP } & Bacteria & 3,600 & \multirow[t]{2}{*}{128} & 0.036 \\
\hline & Invertebrate & 13,000 & & 0.010 \\
\hline
\end{tabular}

MEC: max measured concentrations in river. 
facilitate the degradation of parabens in chlorinated water, resulting in high level of $\sum \mathrm{Cl}$-PBs in surface water.

\subsection{Risk assessment}

Several studies have reported that parabens and their chlorinated derivatives may pose potential hazards to aquatic organisms (Albero et al., 2012; Inui et al., 2003; Terasaki et al., 2013). In this study, seven parabens and two di-chlorinated parabens, were frequently observed in river and lake water samples. Therefore, it is essential to evaluate their ecological risks in the aquatic environment. According to limited data available on the chronic and acute toxicity (Table S6 and S7), HQs of five parabens and two di-chlorinated parabens to various aquatic organisms (bacteria, algae, invertebrate and fish) are shown in Table 3.

Generally, the bacteria $\left(\mathrm{EC}_{50} \mathrm{~s}: 0.16-31 \mathrm{mg} / \mathrm{L}\right)$ are supposed to be more sensitive to parabens, a group of effective preservatives with broad spectrum of antibacterial activity. However, with the exception of $\operatorname{PrP}(\mathrm{HQ}=2.2)$, most $\mathrm{HQ}$ values for bacteria were less than 1, indicating low risk in the surface water of Beijing. As for other three kinds of organisms, algae ( $\left.\mathrm{EC}_{50} \mathrm{~s}: 1.2-80 \mathrm{mg} / \mathrm{L}\right)$, invertebrate $\left(\mathrm{EC}_{50} \mathrm{~s}: 1.9-34 \mathrm{mg} / \mathrm{L}\right)$ and fish $\left(\mathrm{EC}_{50} \mathrm{~s}: 0.73-34.3 \mathrm{mg} / \mathrm{L}\right)$, are not susceptible to parabens and their di-chlorinated derivatives, with all the HQs are lower than 1 by a range of one to three orders of magnitude, suggesting little potential adverse ecological consequences on these aquatic organisms. It should be mentioned that parabens and chlorinated parabens often occur in the aquatic environment as multi-component mixtures, their synergistic effects may lead to higher toxicity risks to the aquatic organisms, so more attention should be paid to the risk of these compounds in the future.

\section{Conclusions}

In this study, seven parabens, four chlorinated parabens and PHBA were detected in 350 surface water samples in Beijing. PHBA and di-chlorinated parabens were widely distributed in surface water in Beijing. MeP and PrP were the dominant parabens in these samples. It is noteworthy that OcP with longer chain was firstly detected in this study. Compared to previous studies, the level of parabens in this study was relatively high. This study showed that untreated sewage discharge was likely the main source of parabens in the high-polluted river. Parabens exhibited a different seasonal variation from chlorinated derivatives. The level of chlorinated derivatives was highest in summer, while the parabens were lowest in this season, which may be due to that more parabens are formed to chlorinated derivatives in chlorinated water in the wet season. At current levels in the surface water of Beijing, parabens and their chlorinated derivatives are not likely to produce biological effects on aquatic ecosystems.

\section{Acknowledgements}

This work was supported by the National Natural Science Foundation of China (No. 21537004, 21407008, 21321004, and 21277011), the Strategic Priority Research Program of the Chinese Academy of Sciences (XDB14010201), the Fundamental Research Funds for the Central Universities (FRF-BR-13-005), China Postdoctoral Science Foundation (2014M550619), and State Key Laboratory of Environmental Chemistry and Ecotoxicology, Research Center for Eco-Environmental Sciences, Chinese Academy of Sciences (KF2013-07).

\section{Appendix A. Supplementary data}

Supplementary data to this article can be found online at http://dx. doi.org/10.1016/j.scitotenv.2015.08.150.

\section{References}

Albero, B., Ana Perez, R., Sanchez-Brunete, C., Luis, T.J., 2012. Occurrence and analysis of parabens in municipal sewage sludge from wastewater treatment plants in Madrid (Spain). J. Hazard. Mater. 239, 48-55.

Alvarez-Rivera, G., Llompart, M., Garcia-Jares, C., Lores, M., 2014. Identification of halogenated photoproducts generated after ultraviolet-irradiation of parabens and benzoates in water containing chlorine by solid-phase microextraction and gas chromatography-mass spectrometry. J. Chromatogr. A 1349, 105-115.

Bazin, I., Gadal, A., Tonraud, E., Roig, B., 2010. Hydroxy benzoate preservatives (parabens) in the environment: data for environmental toxicity assessment. Volucella 16.

Blanco, E., Casais, M.D., Mejuto, M.D., Cela, R., 2009. Combination of off-line solid-phase extraction and on-column sample stacking for sensitive determination of parabens and p-hydroxybenzoic acid in waters by non-aqueous capillary electrophoresis. Anal. Chim. Acta 647, 104-111.

Bledzka, D., Gromadzinska, J., Wasowicz, W., 2014. Parabens. From environmental studies to human health. Environ. Int. 67, 27-42.

Canosa, P., Rodriguez, I., Rubi, E., Negreira, N., Cela, R., 2006. Formation of halogenated by-products of parabens in chlorinated water. Anal. Chim. Acta 575, 106-113.

Dai, G., Wang, B., Huang, J., Dong, R., Deng, S., Yu, G., 2015. Occurrence and source apportionment of pharmaceuticals and personal care products in the Beiyun River of Beijing, China. Chemosphere 119, 1033-1039.

Darbre, P.D., Aljarrah, A., Miller, W.R., Coldham, N.G., Sauer, M.J., Pope, G.S., 2004. Concentrations of parabens in human breast tumours. J. Appl. Toxicol. 24, 5-13.

Darbre, P.D., Harvey, P.W., 2014. Parabens can enable hallmarks and characteristics of cancer in human breast epithelial cells: a review of the literature with reference to new exposure data and regulatory status. J. Appl. Toxicol. 34, 925-938.

Diaz, A.N., Algarra, M., Feria, L.S., Sanchez, F.G., 2008. Fluorimetric determination of p-hydroxybenzoic acid in beer as alpha-cyclodextrin inclusion complex. Anal. Lett. $41,1802-1810$.

Dobbins, L.L., Usenko, S., Brain, R.A., Brooks, B.W., 2009. Probabilistic ecological hazard assessment of parabens using Daphnia magna and Pimephales promelas. Environ. Toxicol. Chem. 28, 2744-2753.

Eriksson, E., Andersen, H.R., Madsen, T.S., Ledin, A., 2009. Greywater pollution variability and loadings. Ecol. Eng. 35, 661-669.

Gasperi, J., Geara, D., Lorgeoux, C., Bressy, A., Zedek, S., Rocher, V., et al., 2014. First assessment of triclosan, triclocarban and paraben mass loads at a very large regional scale: case of Paris conurbation (France). Sci. Total Environ. 493, 854-861.

Gonzalez-Marino, I., Quintana, J.B., Rodriguez, I., Cela, R., 2011. Evaluation of the occurrence and biodegradation of parabens and halogenated by-products in wastewater by accurate-mass liquid chromatography-quadrupole-time-of-flight-mass spectrometry (LC-QTOF-MS). Water Res. 45, 6770-6780.

Gorga, M., Petrovic, M., Barcelo, D., 2013. Multi-residue analytical method for the determination of endocrine disruptors and related compounds in river and waste water using dual column liquid chromatography switching system coupled to mass spectrometry. J. Chromatogr. A 1295, 57-66.

Guo, Y., Kannan, K., 2013. A survey of phthalates and parabens in personal care products from the United States and its implications for human exposure. Environ. Sci. Technol. 47, 14442-14449.

Guo, Y., Wang, L., Kannan, K., 2014. Phthalates and parabens in personal care products from China: concentrations and human exposure. Arch. Environ. Contam. Toxicol. 66, 113-119.

Haman, C., Dauchy, X., Rosin, C., Munoz, J.-F., 2015. Occurrence, fate and behavior of parabens in aquatic environments: a review. Water Res. 68, 1-11.

Harvey, P.W., 2004. Discussion of concentrations of parabens in human breast tumours. J. Appl. Toxicol. 24, 307-310.

Heeb, F., Singer, H., Pernet-Coudrier, B., Qi, W., Liu, H., Longree, P., et al., 2012. Organic micropollutants in rivers downstream of the megacity Beijing: sources and mass fluxes in a large-scale wastewater irrigation system. Environ. Sci. Technol

Hernando, M., Mezcua, M., Fernandezalba, A., Barcelo, D., 2006. Environmental risk assessment of pharmaceutical residues in wastewater effluents, surface waters and sediments. Talanta $69,334-342$.

Hoberg, E., Meier, B., Sticher, O., 2000. An analytical high performance liquid chromatographic method for the determination of agnuside and p-hydroxybenzoic acid contents in agni-casti fructus. Phytochem. Anal. 11, 327-329.

Hou, P.Q., Ren, Y.F., Zhang, Q.Q., Zhang, Y., Wang, H.F., Lu, F., et al., 2013. Temporal and spatial variations of water quality in a trans-urban river in Beijing, China. Fresenius Environ. Bull. 22, 561-572.

Inui, M., Adachi, T., Takenaka, S., Inui, H., Nakazawa, M., Ueda, M., et al., 2003. Effect of UV screens and preservatives on vitellogenin and choriogenin production in male medaka (Oryzias latipes). Toxicology 194, 43-50.

Jonkers, N., Kohler, H.P.E., Dammshauser, A., Giger, W., 2009. Mass flows of endocrine disruptors in the Glatt River during varying weather conditions. Environ. Pollut. 157, 714-723.

Jonkers, N., Sousa, A., Galante-Oliveira, S., Barroso, C.M., Kohler, H.-P.E., Giger, W., 2010. Occurrence and sources of selected phenolic endocrine disruptors in Ria de Aveiro, Portugal. Environ. Sci. Pollut. Res. 17, 834-843.

Kang, S., Kim, S., Park, J., Kim, H.-J., Lee, J., Choi, G., et al., 2013. Urinary paraben concentrations among pregnant women and their matching newborn infants of Korea, and the association with oxidative stress biomarkers. Sci. Total Environ. 461, 214-221.

Karpuzoglu, E., Holladay, S.D., Gogal Jr., R.M., 2013. Parabens: potential impact of lowaffinity estrogen receptor binding chemicals on human health. J. Toxicol. Environ. Health-B-Crit. Rev, 16, 321-335.

Kasprzyk-Hordern, B., Dinsdale, R.M., Guwy, A.J., 2008. The effect of signal suppression and mobile phase composition on the simultaneous analysis of multiple classes of acidic/neutral pharmaceuticals and personal care products in surface water by 
solid-phase extraction and ultra performance liquid chromatography-negative electrospray tandem mass spectrometry. Talanta 74, 1299-1312.

Kimura, K., Kameda, Y., Yamamoto, H., Nakada, N., Tamura, I., Miyazaki, M., et al., 2014. Occurrence of preservatives and antimicrobials in Japanese rivers. Chemosphere 107, 393-399.

Leung, H.W., Minh, T.B., Murphy, M.B., Lam, J.C.W., So, M.K., Martin, M., et al., 2012. Distribution, fate and risk assessment of antibiotics in sewage treatment plants in Hong Kong, South China. Environ. Int. 42, 1-9.

Li, W., Shi, Y., Gao, L., Liu, J., Cai, Y., 2015. Occurrence, fate and risk assessment of parabens and their chlorinated derivatives in an advanced wastewater treatment plant. J. Hazard. Mater. 300, 29-38.

Liao, C., Kannan, K., 2014. Concentrations and composition profiles of parabens in currency bills and paper products including sanitary wipes. Sci. Total Environ. 475C, 8-15.

Liao, C., Lee, S., Moon, H.B., Yamashita, N., Kannan, K., 2013. Parabens in sediment and sewage sludge from the United States, Japan, and Korea: spatial distribution and temporal trends. Environ. Sci. Technol. 47, 10895-10902.

Lin, Y., Ferronato, C., Deng, N., Chovelon, J.-M., 2011. Study of benzylparaben photocatalytic degradation by TiO2. Appl. Catal. Environ. 104, 353-360.

Liu, J., Lu, G., Xie, Z., Zhang, Z., Li, S., Yan, Z., 2015. Occurrence, bioaccumulation and risk assessment of lipophilic pharmaceutically active compounds in the downstream rivers of sewage treatment plants. Sci. Total Environ. 511, 54-62.

Loraine, G.A., Pettigrove, M.E., 2006. Seasonal variations in concentrations of pharmaceuticals and personal care products in drinking water and reclaimed wastewater in southern California. Environ. Sci. Technol. 40, 687-695.

McQualter, R.B., Chong, B.F., Meyer, K., Van Dyk, D.E., O'Shea, M.G., Walton, N.J., et al., 2005. Initial evaluation of sugarcane as a production platform for p-hydroxybenzoic acid. Plant Biotechnol. J. 3, 29-41.

Meeker, J.D., Yang, T., Ye, X.Y., Calafat, A.M., Hauser, R., 2011. Urinary concentrations of parabens and serum hormone levels, semen quality parameters, and sperm DNA damage. Environ. Health Perspect. 119, 252-257.

Mutiyar, P.K., Mittal, A.K., 2014. Risk assessment of antibiotic residues in different water matrices in India: key issues and challenges. Environ. Sci. Pollut. Res. 21, 7723-7736.

Oishi, S., 2002. Effects of propyl paraben on the male reproductive system. Food Chem. Toxicol. 40, 1807-1813.

Peng, X., Yu, Y., Tang, C., Tan, J., Huang, Q., Wang, Z., 2008. Occurrence of steroid estrogens, endocrine-disrupting phenols, and acid pharmaceutical residues in urban riverine water of the Pearl River Delta, South China. Sci. Total Environ. 397, 158-166.

Piao, C., Chen, L., Wang, Y., 2014. A review of the extraction and chromatographic determination methods for the analysis of parabens. J. Chromatogr. B 969, 139-148.

Ramaswamy, B.R., Shanmugam, G., Velu, G., Rengarajan, B., Larsson, D.G.J., 2011. GC-MS analysis and ecotoxicological risk assessment of triclosan, carbamazepine and parabens in Indian rivers. J. Hazard. Mater. 186, 1586-1593.
Ramirez, N., Borrull, F., Maria, M.R., 2012. Simultaneous determination of parabens and synthetic musks in water by stir-bar sorptive extraction and thermal desorptiongas chromatography-mass spectrometry. J. Sep. Sci. 35, 580-588.

Regueiro, J., Becerril, E., Garcia-Jares, C., Llompart, M., 2009. Trace analysis of parabens, triclosan and related chlorophenols in water by headspace solid-phase microextraction with in situ derivatization and gas chromatography-tandem mass spectrometry. J. Chromatogr. A 1216, 4693-4702.

Ren, Y., Xu, Z., Zhang, X., Wang, X., Sun, X., Ballantine, D.J., et al., 2014. Nitrogen pollution and source identification of urban ecosystem surface water in Beijing. Front. Environ. Sci. Eng. 8, 106-116.

Soni, M.G., Carabin, I.G., Burdock, G.A., 2005. Safety assessment of esters of p-hydroxybenzoic acid (parabens). Food Chem. Toxicol. 43, 985-1015.

Terasaki, M., Abe, R., Makino, M., Tatarazako, N., 2013. Chronic toxicity of parabens and their chlorinated by-products in Ceriodaphnia dubia. Environ. Toxicol. http://dx.doi. org/10.1002/tox.21944.

Terasaki, M., Kamata, R., Shiraishi, F., Makino, M., 2009a. Evaluation of estrogenic activity of parabens and their chlorinated derivatives by using the yeast two-hybrid assay and the enzyme-linked immunosorbent assay. Environ. Toxicol. Chem. 28, 204-208,

Terasaki, M., Makino, M., 2009. Disinfection by-products of para-hydroxybenzoate esters (parabens): synthesis and mass spectrometric study. J. Health Sci. 55, 631-635.

Terasaki, M., Makino, M., Tatarazako, N., 2009b. Acute toxicity of parabens and their chlorinated by-products with Daphnia magna and Vibrio fischeri bioassays. J. Appl. Toxicol. 29, 242-247.

Terasaki, M., Takemura, Y., Makino, M., 2012. Paraben-chlorinated derivatives in river waters. Environ. Chem. Lett. 10, 401-406.

Wang, B., Dai, G., Deng, S., Huang, J., Wang, Y., Yu, G., 2015. Linking the environmental loads to the fate of PPCPs in Beijing: considering both the treated and untreated wastewater sources. Environ. Pollut. 202, 153-159.

Wei, J., Ye, B., Wang, W., Yang. L., Tao, J., Hang, Z., 2010. Spatial and temporal evaluations of disinfection by-products in drinking water distribution systems in Beijing, China. Sci. Total Environ. 408, 4600-4606.

Westerhoff, P., Yoon, Y., Snyder, S., Wert, E., 2005. Fate of endocrine-disruptor pharmaceutical, and personal care product chemicals during simulated drinking water treatment processes. Environ. Sci. Technol. 39, 6649-6663.

Yamamoto, H., Tamura, I., Hirata, Y., Kato, J., Kagota, K., Katsuki, S., et al., 2011. Aquatic toxicity and ecological risk assessment of seven parabens: individual and additive approach. Sci. Total Environ. 410, 102-111.

Yan, C., Yang, Y., Zhou, J., Liu, M., Nie, M., Shi, H., et al., 2013. Antibiotics in the surface water of the Yangtze Estuary: occurrence, distribution and risk assessment. Environ. Pollut. 175, 22-29.

Zhao, X., Fang, Y., 2005. An experimental and theoretical study on the states of PHBA in aqueous solution. J. Mol. Struct. 752, 198-202. 